\title{
Public health monitoring using Geographic Information Systems: case viral hepatitis $\mathrm{E}$
}

\author{
El Omari Hajar ${ }^{*}$, Abdelkader Chahlaoui ${ }^{1}$, Ouarrak Khadija ${ }^{1}$, Adel Kharroubi ${ }^{2}$ \\ ${ }^{1}$ Natural Resources Management and Development Team, Laboratory of Health and Environment, Faculty of Sciences, Moulay Ismail \\ University, Meknes, Morocco \\ 2 institut supérieur des sciences et techniques de l'eau. Université de Gabès.
}

\begin{abstract}
Among the major parasitic diseases having major health and socio-economic impacts in the world and in Morocco, are viral hepatitis. These are acute inflammations of the liver caused by a virus. The 3 most frequently encountered viruses are viruses A, B, C. The objective of this study is to map health events, in our case the incidence of viral hepatitis $\mathrm{E}$ in the different prefectures of the region of Meknes-Fez by creating a database containing geographic and health parameters in geographic information system (GIS). This database was then used to create the risk map which identifies the high-risk prefectures.

This study shows that the average incidence of viral hepatitis $\mathrm{H}$ is higher in the prefecture of Meknes during all the years of the study, with a high risk compared to other prefectures and provinces which have an average risk. Indeed, the mapping of health events is a descriptive tool implemented to evaluate the spatial disparities of incidence, which allowed us to perform a spatio-temporal analysis of the epidemic.

Spatial technologies, such as geographic information systems (GIS), offer a new option for disease prevention, predicting risk locations based on factors favoring the emergence or re-emergence of the epidemic.

keywords: Geographic Information System (GIS), Health risk, Epidemiology, viral hepatitis E, Morocco
\end{abstract}

\section{Introduction}

Viral hepatitis is an inflammation of the liver [1], caused by one of the five hepatitis viruses: A, B, C, D or E [2]. These viruses are transmitted by various routes: by ingestion of contaminated food or water for hepatitis A and E; by contact with unsafe blood or other body fluids for hepatitis $\mathrm{B}$; mainly by contaminated blood for hepatitis $\mathrm{C}$; as for hepatitis $\mathrm{D}$, it is an additional infection that occurs in the presence of hepatitis B.

Viral hepatitis, in particular E, is a disease closely related to environmental factors. This group of diseases where the causal agent is transmitted to humans through water or food seems inevitably related to the reuse of wastewater in agriculture $[3,4]$. These viruses occupy a prominent place in the morbidity of the population, which explains the important research efforts currently being made to understand and treat these infections. Viral hepatitis $\mathrm{E}$ is recognized as a disease with a wide geographical distribution, responsible for more than 50\% of viral hepatitis cases observed in young and middleaged adults residing in the third world [5].

It is in this perspective that the present study aims to map the hepatitis E epidemic in the region of Fes Meknes in order to highlight the role of geographic information systems in the surveillance of diseases or epidemics.

\section{Materiel and methods}

\section{1 study area}

The region of Fés-Meknés (figure 1) is one of the regions of Morocco, located in the North Center. It covers an area of $40,075 \mathrm{~km}^{2}$, representing $5.7 \%$ of the surface area of the Kingdom.

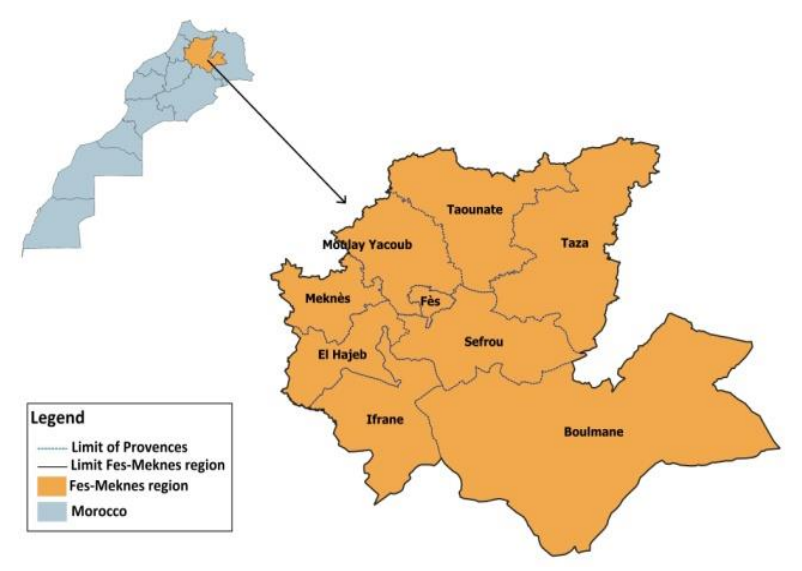

Fig. 1. Study area

\footnotetext{
* Corresponding author: elomari.hajar.gie@gmail.com
} 
The Region is composed of 2 prefectures (Fez and Meknes) and 7 provinces (Taounate, Taza, Sefrou, El Hajeb, Boulemane, My Yacoub and Ifrane).

\subsection{Data acquisition}

To highlight the usefulness of GIS in public health surveillance it is important to integrate health data into a geographic information system. In our case we used the Qgis software. The raw data for this study was extracted from the prefectural epidemiology cell of the CPE on the number of viral hepatitis cases recorded during the period 2011

\subsection{Data processing}

To achieve our objectives we first calculated the incidence by dividing the number of new cases of disease in a given period of time by the population at risk. Then we calculated the average cumulative incidence during the study period

Ic avg $=$ Ic (2011)+ Ic (2012)+ Ic (2013)+ Ic (2014)+ Ic $(2015) / 5$

In order to move from the language of epidemiological sciences to that of geographic information sciences, we used the technique of "Scoring" based on the calculation of the mean and standard deviation.For the purpose of standardization, the scores are calculated as follows:

Table 1. Methode of scoring

\begin{tabular}{|c|c|c|}
\hline Score & valeur & Level risk \\
\hline 1 & Ic avg $<\mu-\sigma$ & low \\
\hline 2 & $\mu-\sigma \leq$ Ic avg $\leq \mu+\sigma$ & Medium \\
\hline 3 & Ic avg $>\mu+\sigma$ & High \\
\hline
\end{tabular}

$\mu$ : The mean of the cumulative incidence $\sigma$ : standard deviation

Ic avg : average cumulative incidence

\section{Results}

\subsection{Distribution of viral hepatitis $E$ in the Fez- Meknes region}

The analysis of the distribution of viral hepatitis in the region of Fez-Meknes (figure 2) showed that the largest percentage was recorded in the prefecture of Meknes with $53 \%$ followed by the province moulay akoub $13 \%$.

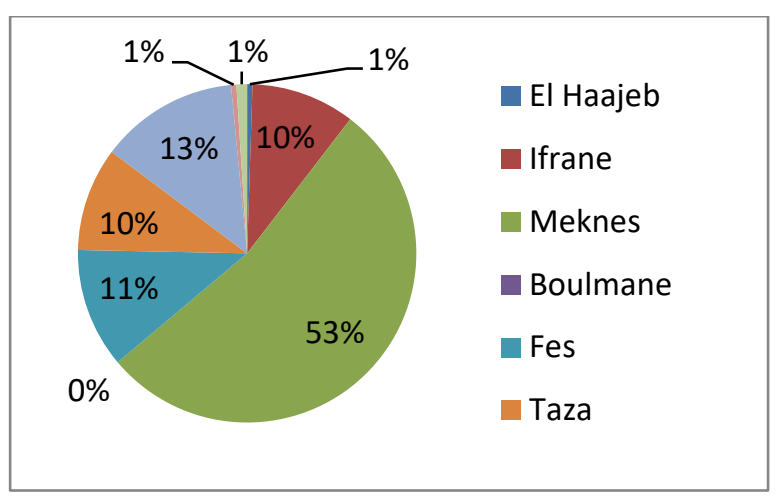

Fig.2.Distribution of viral hepatitis E in the Fez-Meknes region.

In fact the average cumulative incidence of HVE is important in the prefecture of Meknes followed by Moulay yakoub (Figure 3).

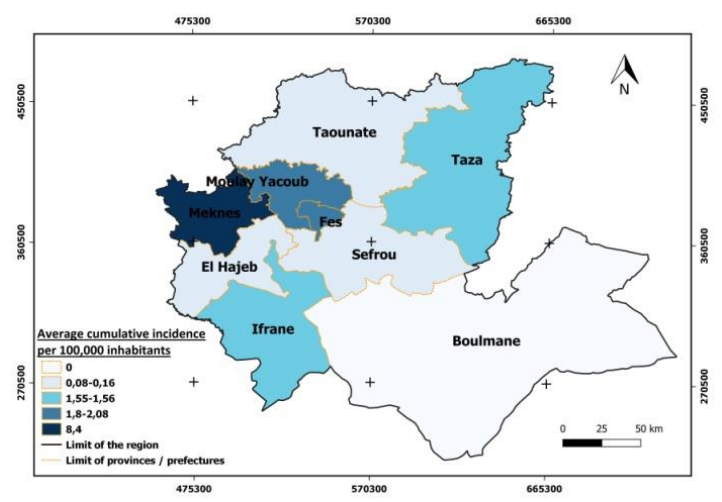

Fig.3. Average Cumulative Incidence of HVE (2011-2015) in the Fez-Meknes region.

\subsection{Spatial and temporal distribution of viral hepatitis $E$}

The spatio temporal distribution of hepatitis (figures 4,5 , $6,7,8)$ reveals a spatio temporal mobility of the incidence peaks unevenly in the region Fes meknes. It is also important to note that the average incidence of this disease in the prefecture of meknes meknes is higher during all years of the study.

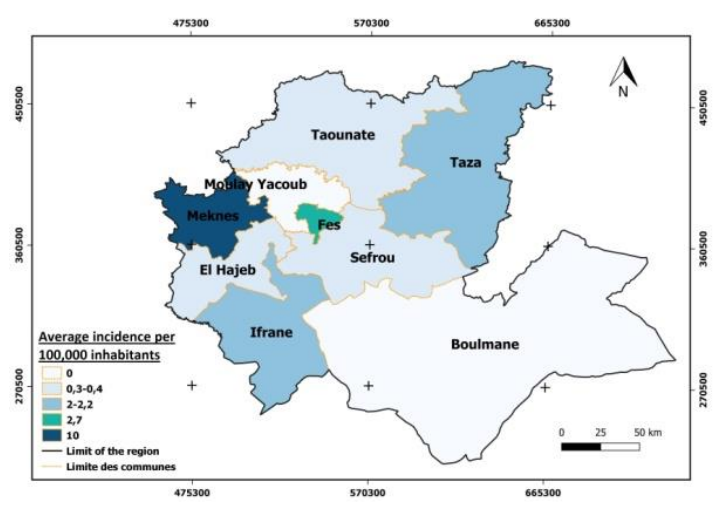

Fig.4. Average incidence of VHE in 2011. 


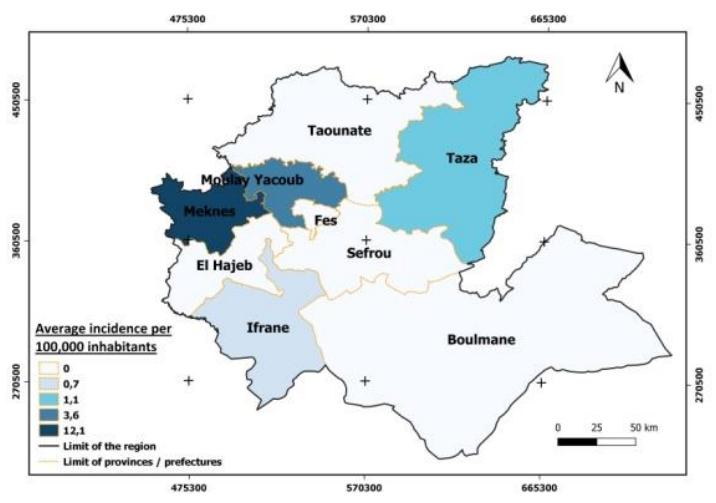

Fig.5. Average incidence of VHE in 2012.

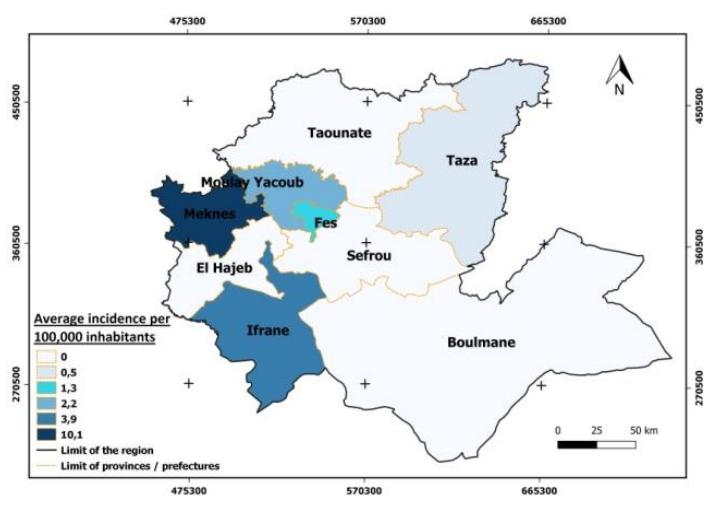

Fig.6. Average incidence of VHE in 2013.

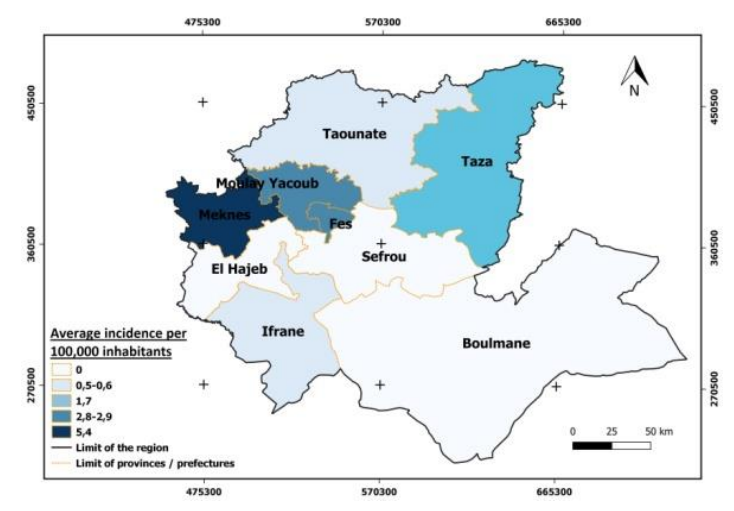

Fig.7. Average incidence of VHE in 2014.

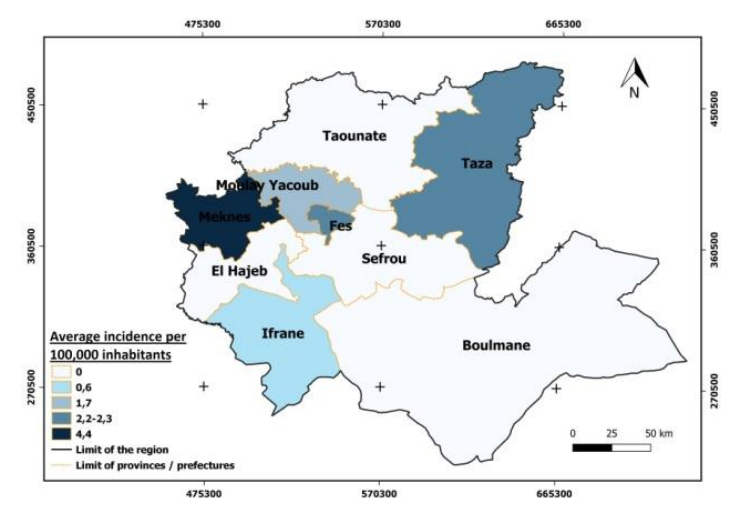

Fig.8. Average incidence of VHE in 2014.

\subsection{Health risk map}

The health risk map of viral hepatitis E (Figure 9) shows that with the exception of the prefecture of Boulmane, which did not record any cases during the five years of study, the other provinces are all at medium risk and the prefecture of Meknes at high risk.

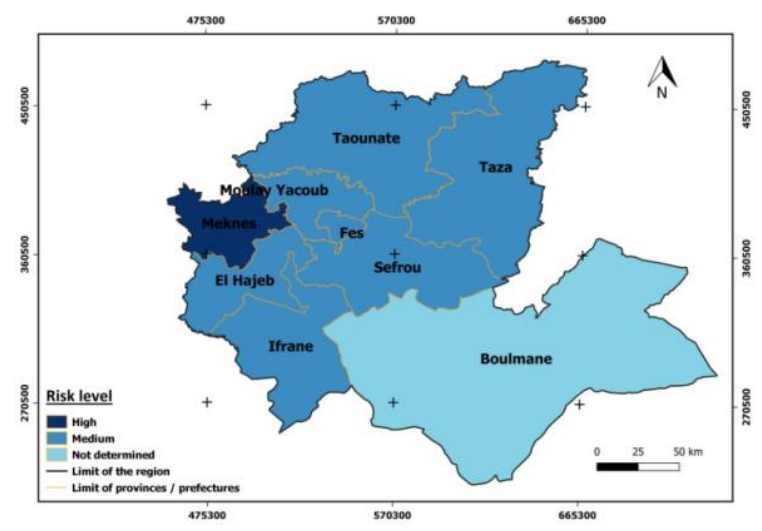

Fig.9. Health risk map of viral hepatitis E in Fes-Meknes region.

\section{Discussion}

HEV is a leading cause of acute hepatitis in adults in underdeveloped and developing countries [6]. Each year, an estimated 20 million HEV infections occur worldwide, generating an estimated 3.3 million symptomatic cases of hepatitis E [7].The virus is transmitted via the fecal-oral route, mainly through contaminated water. Worldwide, an estimated 20 million hectares are irrigated with wastewater, and of these, the majority is untreated [8].

In several developing countries, such as Morocco, wastewater has been used as a source of crop nutrients for many decades [3,9]. Consequently, the agricultural use of untreated wastewater has been associated with land application and crop production for centuries [10]. This causes epidemics of waterborne diseases in general and HVE in particular is still a health hazard.

In our study area, we notice a strong existence of this disease in the prefecture of Meknes (\%) followed by the province of Meknes (\%).

Similarly, the average incidence during the study years of HVE does not have a homogeneous distribution throughout the region. The province of Meknes records the highest values, followed by the province of $\mathrm{Fez}$. While the average incidence falls considerably in the province Boulmane (no cases were recorded during this period). It is interesting to note that the prefecture of meknes has always been affected This could be explained by the fact that the irrigation of urban and peri-urban agriculture in Meknes is supported by three rivers: Bouisshak in the west, Boufekrane in the middle and Ouislane in the east. These wadis are characterized by a relatively low flow rate, which leads to dependence on other irrigation resources including: raw or mixed wastewater [11]. 
The study of irrigated agricultural areas shows that the area irrigated by wastewater and mixed water in the three sectors (Bouisshak, Ouislane and Boufekrane) reach $95.4 \%$ of the total area surveyed, with a dominance of areas irrigated by wastewater $(77.5 \%)$. The consumption of food irrigated by wastewater poses health risks since it can be the vector of pathogens associated with excreta, $[12,13]$. The reuse of urban wastewater is a real practice in the Meknes region. It is obviously carried out from wastewater discharged, without treatment, in the 3 wadis crossing the city.

Thus, several crops produced, essentially market garden produce and in particular raw vegetables, directly and regularly feed the informal markets that abound in the city. This is considered a real threat to public health.

A global study on the hidden practice of wastewater irrigation reveals that sewage water, often untreated, is used for the production of $10 \%$ of the world's crops, especially in urban areas [4]. In several countries, this practice constitutes a means of subsistence and generates considerable income in urban and peri-urban agriculture, despite the health and environmental risks associated with the use of wastewater in irrigation. Indeed, the lack of sanitary facilities and appropriate evacuation infrastructure in cities is one of the direct causes of such pollution and use [14].

The sanitary risk map has allowed us to identify the prefectures/provinces at risk, which allows us to put in place prevention and intervention measures for an effective fight $[15,16]$.This type of map can offer interesting perspectives to safety/security managers and is perfectly in line with the different approaches that can be implemented by the state in this sector. Mapping can participate in the global management of risks in order to evaluate the exposure of a Region to risks and to ensure its protection as well as the continuity of its activities [17].

\section{Conclusion}

In light of these results, we can conclude that the mapping of health phenomena, using geographic information systems such as QGIS, allows us to provide the general public and decision-makers with privileged tools for communication and data analysis. These maps, like the health risk map, allow us to set up rapid and efficient intervention strategies.

\section{References}

1. MJ. Alter, EE. Mast. The epidemiology of viral hepatitis in the United States. Gastroenterol Clin North Am.23, 437-455 (1994)

2. F. BARIN. le virus isolé de patient TT(TTV):toujours orphelin deux années après sa découvite. Transfus clin Biol.7:79-83. (2000)

3. B. Jiménez, et $\mathrm{T}$. Asano «Water reclamation and reuse around the world», dans B. Jiménez et coll. (dir.), Water Reuse : An International Survey of Current Practice, Issues and Needs, Londres, IWA Publishing, p. 648. (2008).
4. C. A. Scott, N. I. Faruqui et L. Raschid-Sally «Wastewater use in irrigated agriculture: Management challenges in developing countries», dans C. A. Scott et coll. (dir.), Wastewater Use in Irrigated Agriculture : Confronting the Livelihood and Environmental Realities, Wallingford, CABI Publishing, p. 1-10. (2004).

5. II.BRADLEY, Hepatitis E virus: a briefreview ofthe biology, molecular viralogy, and immunology of a novel virus J Hepatol.22 140145. 1995

6. S. Pattanayak Magnitude of the problem of hepatitis and directions for research, prevention and control. WHO regional office for South-East Asia, New Delhi, 1986

7. DB. Rein, GA. Stevens, J. Theaker, JS. Wittenborn, ST. Wiersma. The global burden of hepatitis E virus genotypes 1 and 2 in 2005 . Hepatology.55(4):988-97 (2012).

8. T. Asano, F. Burton, H. Leverenz, R. Tsuchihashi,. Tchobanoglous, Water reuse : issues, technologies, and applications. New York (US): Metcalf \& Eddy (2007).

9. AATSE (2004). Water recycling in Australia. Melbourne, Australian Academy of Technological Sciences and Engineering.

10. B. Keraita, P. Drechsel, F. Konradsen, Perceptions of farmers on health risks and risk reduction measures in wastewater-irrigated urban vegetable farming in Ghana. Journal of Risk Research - J RISK RES. 11. 10471061(2008).

11. M. Abdouh, A. El Atrouz, A. Mechkouri. Profil environnemental de Meknès, Agendas 21 locaux pour la promotion de l'environnement et du développement durable en milieu urbain, Rabat : Ministère de I'Aménagement du Territoire, de I'Eau et de l'Environnement.) (2004).

12. R. Bos, R. Carr, B. Keraita, , Évaluer et atténuer les risques sanitaires associés aux eaux usées dans les pays à faible revenu, In Drechsel $\mathrm{P}$. , Scott C., Raschid-Sally L., Redwood M. , Bahri A., L'irrigation avec des eaux usées et la santé: évaluer et atténuer les risques dans les pays à faible revenu, Canada: Presses de I'Université du Québec, pp 31-50.( 2011).

13. Organisation Mondiale de la Santé (OMS), Directives OMS pour I'utilisation sans risque des eaux usées, des excreta et des eaux ménagères, Volume II : Utilisation des eaux usées en agriculture, Genève : Organisation Mondiale de la Santé. (2012). 
14. L. Raschid-Sally, P. Jayakody Drivers and Characteristics of Wastewater Agriculture in Developing Countries: Results From a Global Assessment, Colombo, Sri Lanka, IWMI Research Report 127, Colombo, Institut international de gestion de l'eau. (2008).

15. H. El Omari, A. Chahlaoui, A. Oualialami, M.khafou. The contribution of geographic information systems in the fight against parasitic diseases: the case of Leishmaniasis. SCA '18: Proceedings of the 3rd International Conference on Smart City Applications. 1-5. (2018).

16. H. El Omari, A. Chahlaoui, A. Taouraout, A. Oualialami Geographical information systems (GIS) and epidemiology of vector diseases: case of leishmaniasis in the Fez-Meknes, region of Morocco. SCA '19: Proceedings of the 4th International Conference on Smart City Applications. 1-4. (2019).

17. B. Cornélis, R. Billen La cartographie des risques et les risques de la cartographie, in P. Hupet (ed.), Risque et systèmes complexes: Les enjeux de la communication, P.I.E.-Peter Lang. 207-222. (200) 